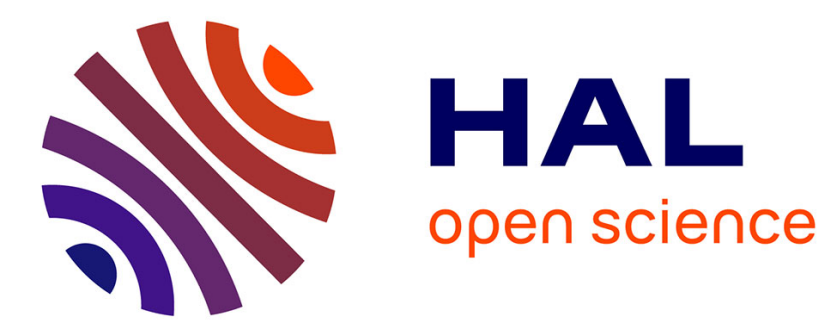

\title{
Study of fast photoprocesses in biomolecules with the aid of a femtosecond laser spectrometer
}

\author{
S.V. Chekalin, Yu. A. Matveets, A.P. Yartsev
}

\section{To cite this version:}

S.V. Chekalin, Yu. A. Matveets, A.P. Yartsev. Study of fast photoprocesses in biomolecules with the aid of a femtosecond laser spectrometer. Revue de Physique Appliquée, 1987, 22 (12), pp.1761-1771. 10.1051/rphysap:0198700220120176100 . jpa-00245737

\section{HAL Id: jpa-00245737 https://hal.science/jpa-00245737}

Submitted on 1 Jan 1987

HAL is a multi-disciplinary open access archive for the deposit and dissemination of scientific research documents, whether they are published or not. The documents may come from teaching and research institutions in France or abroad, or from public or private research centers.
L'archive ouverte pluridisciplinaire HAL, est destinée au dépôt et à la diffusion de documents scientifiques de niveau recherche, publiés ou non, émanant des établissements d'enseignement et de recherche français ou étrangers, des laboratoires publics ou privés. 


\title{
Study of fast photoprocesses in biomolecules with the aid of a femtosecond laser spectrometer
}

\author{
S.V. Chekalin, Yu. A. Matveets and A.P. Yartsev \\ Institute of Spectroscopy, USSR Academy of Sciences, 142092 Troitsk, Moscow Region, U.S.S.R.
}

(Reçu le ler juin 1987, révisé le 8 octobre 1987, accepté le 9 octobre 1987)

\begin{abstract}
Résumé. - Cet article décrit le spectromètre laser femtoseconde utilisé à l'Institut de Spectroscopie de l'Académie des Sciences de l'URSS pour des expériences de spectroscopie ultrarapide avec les molécules biologiques. On présente les résultats des études expérimentales sur des photo-processus primaires dans les centres réactifs, intacts et modifiés, de la bactérie pourpre. Les expériences ont montré que le processus de séparation de charges implique la participation de la bactériochlorophylle monomère.
\end{abstract}

\begin{abstract}
The paper describes the femtosecond laser spectrometer used at the Institute of Spectroscopy, USSR Academy of Sciences, to carry out ultrafast spectroscopic experiments with biomolecules and presents the results of experimental studies of the primary photoprocesses occurring in the reaction centres, both intact and modified, of purple bacteria. The experiments have shown that the charge separation process proceeds with the participation of monomer bacteriochlorophyll.
\end{abstract}

\section{Introduction.}

To solve many a problem in physics, chemistry, biology, and a variety of allied fields requires that the processes of interest should be investigated with a time resolution on a picosecond and even femtosecond scale. Such problems include, for example, the studies of the primary photosynthesis processes, coherent nonlinear effects in condensed media, and relaxation processes in complex organic molecules.

One of the most powerful methods of studying the above processes is ultrafast spectroscopy. The considerable progress made recently in the ways to generate ultrashort light pulses has allowed these pulses to be used to build spectrometers for kinetic investigations with a time resolution as high as $10^{-13}-10^{-14} \mathrm{~s}$.

The spectrometer is built around a femtosecondpulse laser. For many applications it is necessary that the laser frequency should be capable of being converted, and for this reason the pulse power should be high enough to ensure a high conversion ratio. This requirement governs the choice of the laser system : an oscillator plus a multistage amplifier. The active medium of both the oscillator and the amplifier stages is a dye solution, because it is exactly this type of laser that allows the shortest pulses to be obtained. What is more, the dye laser has the merit of a very high stability as regards the pulse shape and width, which is of special importance in kinetic spectroscopy. This makes dye lasers compare favorably with solid-state picosecond-pulse lasers in which the shape and duration of pulses fluctuate from shot to shot by virtue of the very nature of generation of such pulses $[1,2]$.

Amplified pulses can be used in a wide variety of spectroscopic techniques. In the double-beam absorption spectroscopy, a powerful subpicosecond pulse is divided into two channels - exciting and probing. The exciting pulse induces absorption changes in the sample, which are registered in a broad spectral region by means of instrumentation measuring the instantaneous transmission of the sample with various delay times. The measurements are taken with the aid of the probing pulse which is converted by nonlinear optics techniques into a very broadband pulse $[3,4]$.

A necessary requirement of the laser used in the spectrometer system is the stability of the pulse parameters (duration and temporal structure, 
wavelength, divergence, and output energy) throughout the experiment (10-12 hours).

The femtosecond laser spectrometer developed at the Institute of Spectroscopy of the USSR Academy of Sciences made it possible to carry out a number of investigations of the primary photoprocesses occurring in various biomolecules. Thus, for example, in experiments with bacteriorhodopsin we observed changes in the absorption of the sample in the spectral range $410-750 \mathrm{~nm}$ during a time interval of 0.5-10 ps after the excitation moment. In this way we managed to monitor all stages of the primary transformation of bacteriorhodopsin, starting with its excited state [5-7]. This paper presents the results of experimental studies of the ptimary photoprocesses occurring in bacterial reaction centres (RC), performed in the past two years.

\section{Femtosecond laser spectrometer.}

A schematic diagram of the femtosecond laser spectrometer used in our experiments is shown in figure 1. It consists of a master oscillator, an amplifier, and a registering system (the spectrometer proper).

\section{MASTER OSCILLATOR}

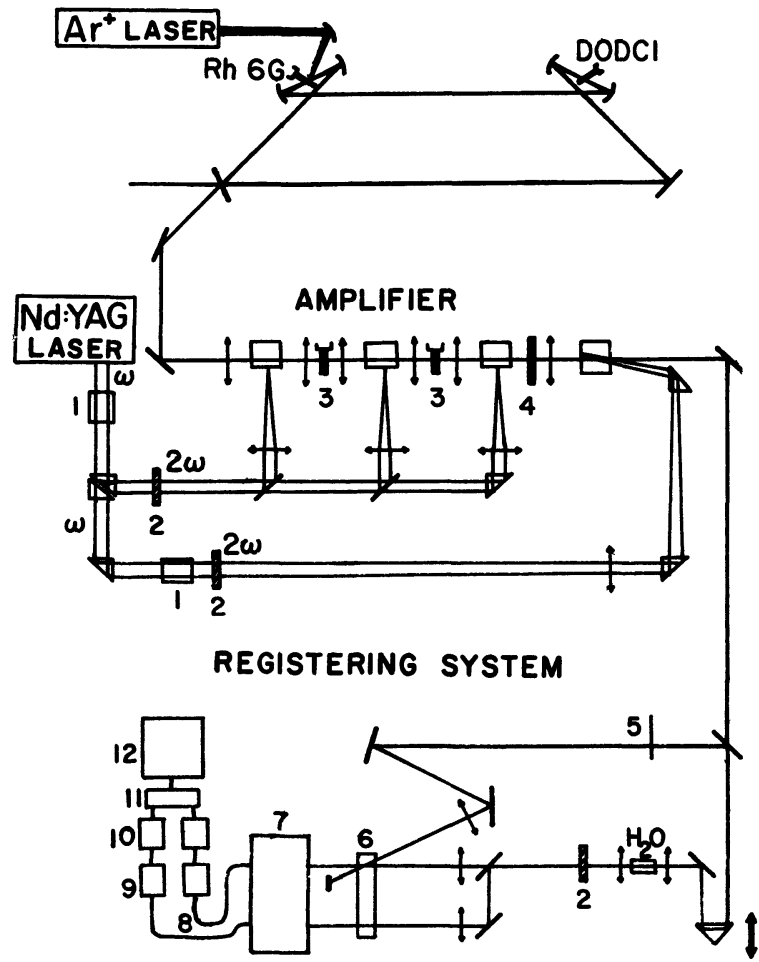

Fig. 1. - Schematic diagram of femtosecond spectrometer 1 - KDP crystals ; 2 - filters ; 3 - Malachite green jets ; 4 - Type RG-8 filter; 5 - shutter ; 6 - sample ; 7 - monochromator ; 8 - optical fibers ; 9 - photoelectronic multipliers ; 10 - digital voltmeters ; 11 - interface ; 12 - microcomputer.
2.1 Dye laser oscillator. - The femtosecondpulse dye laser oscillator consists of an amplifying component (an $\mathrm{Ar}^{+}$-laser-pumped ethylene glycol solution of Rhodamine $6 \mathrm{G}$ ) and an absorbing component (an ethylene glycol solution of the DODCI dye). Both components are placed in an optical cavity.

At the initial stage of the work we studied an oscillator system in which a mixture of both components was pumped to flow in one and the same jet located in a linear cavity [8]. Such an oscillator turned out to be not stable enough : the temporal structure of emission varied and single pulses were produced but rarely. It should be noted that the complex temporal structure of the generated pulses could only be observed with the aid of a streak camera. With the camera operated at a frequency of $1 \mathrm{~Hz}$, we observed single pulses during the axial period only in about $10 \%$ of cases, nonrecurrent groups of chaotically arranged short pulses being observed in the rest of the cases. Observing the autocorrelation function did not allow us to reveal this complex temporal structure, for extra pulses resulted only in some rise of the "wings" of the narrow integral peak. As a final version we chose a ring oscillator system with « colliding » pulses [5,9] in which the amplifying and absorbing components were pumped to flow in separate jets located at a distance of $1 / 4$ of the cavity length from each other. It was demonstrated in a number of works $[10,11]$ that such a scheme possessed a maximum stability.

Examination of the temporal structure of the ring oscillator emission by means of a streak camera (Agate) showed that the laser stably generated single pulses every $12 \mathrm{~ns}$ with a contrast no worse than $10^{5}$. The pulse width (measured with a KDP-crystalbased correlator) did not exceed $10^{-13} \mathrm{~s}$ and the average output power was $10^{-2} \mathrm{~W}$. The oscillator bandwidth was $10 \mathrm{~nm}$ at a wavelength of $620 \mathrm{~nm}$.

2.2 AMPLIFIER. - The oscillator pulse energy is $10^{-10} \mathrm{~J}$. Many experiments, especially those involving frequency conversion, require much higher energies. To amplify the oscillator pulses, we developed a four-stage dye laser amplifier. The active medium in all the amplifier stages was an ethanol solution of the FN-70 Grade dye. The amplifying medium was pumped with 8-ns second harmonic $(\lambda=530 \mathrm{~nm})$ pulses from an $\mathrm{Nd}$ :YAG laser. The energy in each pumping channel amounted to some $50 \mathrm{~mJ}$.

The first three amplifier stages were in the form of $1 \mathrm{~cm}$ thick quartz cells set at the Brewster angle with respect to the radiation being amplified, the same ethanol solution of the FN-70 Grade dye being pumped through all of them. The radiation to be amplified was focused with an objective lens and a number of other lenses into the amplifier stages so as to make its waist measure 100,300 , and $500 \mu \mathrm{m}$ 
across in the first, second, and third stages, respectively. In this case, amplification saturation was obtained, which greatly improved the output energy stability. To reduce absorption losses, the beam to be amplified was passed close to that wall of each cell through which the pumping radiation was impinging. The first three amplifier stages used a transverse pumping scheme. Placed between the amplifier stages were decoupling filters in the form of jets of an ethylene glycol solution of Malachite green used after the first and the second amplifier stage and a red filter, type RG-8 placed after the third cell. The beam was $25 \mu \mathrm{m}$ and $200 \mu \mathrm{m}$ across in the first and second decoupling filters, respectively. Both jet filters used one and the same Malachite green solution $10^{-2} \mathrm{M}$ in concentration. The fourth amplifier stage used a longitudinal pumping scheme. The pulse energy at the output of the amplifier reached a millijoule. But at energies close to the maximum we frequently observed heavy distortions of the spatial and spectral characteristics of the output radiation: the pulse divergence greatly increased and its spectrum broadened several times over. This was apparently due to self-focusing and other nonlinear effects occurring in the output amplifier stages. For this reason, our experiments were usually performed in conditions where the amplified pulse energy did not exceed a few tenths of a millijoule. The width of the amplified pulse, determined in the experiments described later in the text, was around $300 \mathrm{fs}$, which was much greater than in the oscillator. The pulse stretching upon amplification may be due to both linear and nonlinear dispersion in the optical elements of the amplifier. The signal-to-noise ratio at the output was no less than $10^{4}$.

\subsection{REGISTRATION SYSTEMS (ABSORPTION SPEC-} TROMETER). - The amplified pulse was divided into two channels one of which was used to excite the sample and the other to probe the induced absorption changes. The probing pulse used in the spectrometer was a subpicosecond continuum produced upon focusing a powerful pulse into a $2 \mathrm{~cm}$ long water-filled cell. After that the probing pulse was divided into two - a test probing pulse and a reference probing pulse. The test probing pulse was matched with the exciting pulse in the sample, while the reference probing pulse passed outside the excitation region. In this way it was possible to measure precisely the induced absorption. Varying the delay time between the exciting and probing pulses made it possible to monitor the kinetics of the process induced in the sample, and using a monochromator (Model MDR-3) allowed changes in the absorption spectrum of the sample to be studied at the wavelengths of interest. The possible wavelength selection range was determined by the subpicosecond continuum spectrum limited on both the UV and IR sides by the absorption bands of water. The signal after the monochromator was registered with a photoelectric multiplier. The electric pulses thus obtained were fed to pulse voltmeters. The use of an adapter system (interface) made it possible to enter data into a control computer which accumulated and averaged them, calculated errors, and controlled the spectrometer. To estimate the long-term drift of the test-to-reference signal ratio (in the case of biological objects, such changes are mainly due to scattering upon precipitation of the sample), we measured the optical density variation.

$\Delta A(\lambda, \Delta t)=\log \left(T / T_{0}\right)=\log \left[\left(I_{\text {test }}^{*} / I_{\text {ref }}\right)\left(I_{\text {ref }}^{0} / I_{\text {test }}\right)\right]$

where $T=I_{\text {test }}^{*} / I_{\text {ref }}$ and $T_{0}=I_{\text {test }} / I_{\text {ref }}^{0}$ are the test-toreference signal ratios in the presence and absence of excitation, respectively. The switching of the exciting pulse on and off was effected by a control pulse sent by the computer every time a fresh batch of data had been entered and processed.

It can be seen that the result is determined by the values of four quantities obtained in the course of two laser shots. These values were entered into the memory of the computer which calculated $\Delta A(\lambda, \Delta t)$. Statistical errors made it impossible to determine the quantity accurately enough in a single measurement cycle. After carrying out the necessary number (50-60) of repeated measurements, we calculated the average variation $\Delta A_{\mathrm{av}}(\lambda, \Delta t)$ and the mean-square error $\delta(\Delta A)$.

\section{Study of primary photoprocesses occurring in Reaction Centres of purple bacteria.}

The ultrafast processes occurring in the photosynthesis RC's were studied in practically all of the bestknown laboratories throughout the world equipped with femtosecond flash-photolysis setups [11-27]. The interest in such investigations is not accidental, for it is precisely in these RC's that one of the key events of photosynthesis takes place, namely, the conversion, with an almost $100 \%$ quantum efficiency, of the energy of an absorbed light quantum into the energy of separated charges. Detailed studies of the sequence of processes occurring in RC's immediately after the absorption of a light quantum are therefore essential to the understanding and modeling of the natural photosynthesis process. On the other hand, RC's in themselves are very interesting physical objects. In the recent works [2830], they managed to reveal by the X-ray structure analysis techniques the structure of the RC's of some purple bacteria. The RC's of Rhodobacter sphaeroides that were most extensively studied by physical methods include 6 molecules of porphyrine nature, 2 quinone molecules, and a nonheme $\mathrm{Fe}$ atom, all 
attached to a membrane with protein $\alpha$-helices. Each RC contains 4 bacteriochlorophyll molecules (two of them, $B_{L}$ and $B_{M}$ being monomers and the other two forming a dimer, $\mathrm{P}$ ) and 2 bacteriopheopbytin molecules $\mathrm{H}_{\mathrm{L}}$ and $\mathrm{H}_{\mathrm{M}}$. These pigments are arranged symmetrically about the $\mathrm{P}-\mathrm{Fe}$ axis and form two branches: $P-B_{L}-H_{L}-Q_{L}$ and $P-B_{M}-H_{M}-Q_{M}$ (Fig. 2). The subscripts $L$ and $M$ denote noncovalent bonds between the respective pigments and the $\mathrm{L}$ - or M-polypeptides forming the protein $\alpha$-helices. The distances $(\simeq 10 \AA)$ between the adjacent pigments are commensurable with their own size, and therefore the pigments strongly interact with one another. From the standpoint of physics, it is of interest to study under various conditions the processes of energy and charge transfer between the pigments of such a system not unlike an aperiodic crystal.

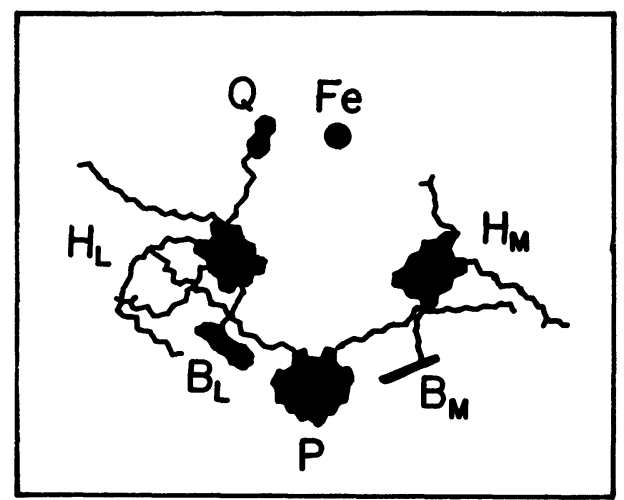

Fig. 2. - Structure of RC pigments of purple bacteria.

To establish the action mechanism of RC's in the course of natural photosynthesis, it is necessary to reveal the role of all their structural components in the energy and charge transfer processes and determine the sequence and rates of these processes. It is exactly to this aspect that most of the studies of bacterial RC's known from the literature are devoted. The experiments [31] on the double electronnuclear resonance have shown that the primary electron donor in the charge transfer process is the dimer $\mathrm{P}$. The electron transfer from the primary donor to the quinone $\mathrm{Q}$ goes on only along the L-branch [32]. The role of the pigments in the M-branch of RC's is as yet unknown.

The primary processes in RC's occur on a time scale of the order of a few picoseconds or shorter $[11-27,33]$ and therefore special technique are required to study them. One such techniques is redox titration which makes it possible to block chemically some stage of a process and observe the accumulation of the product from the preceding stages [34]. This method allows one to reconstruct the sequence of transformations of various intermediates. However, the charge resulting from the chemical reduction or oxidation of the pigments in RC's may appreciably change the rate (see later in the text) and possibly the sequence of the processes.

To study the primary processes occurring in RC's, use was made in the past decade of the picosecond laser spectroscopy techniques which essentially boil down to the excitation of RC's with a pulse 5-40 ps in width, observing the induced luminescence or probing the induced absorption changes by means of the same pulse but delayed and frequency-converted. In most of the works the changes observed were interpreted as resulting from an electron transfer from $P$ to $H_{L}$ within 3-7 ps $[35,36]$ and then from $H_{L}$ to $Q_{L}$ within $100-250$ ps $[33,37-41]$. At the same time, evidence was obtained pointing to the occurrence of a fast transfer of an electron from $P$ to $P_{L}$ preceding the electron transfer to $H_{L}[33,42-$ 45]. Other opinions were also stated: thus, in the work reported in [46], they inferred from experimental data that pheophytin played no part in the charge transfer process.

The discrepancy between the results obtained by different authors is due to their using insufficiently short pulses. Of course, it is in principle possible to investigate fast processes by means of pulses with durations in excess of the characteristic times of the processes. In this case, however, it is not only necessary that the pulse parameters should be highly stable, but, for mathematical processing of data, use should be made of some a priori model, the number of the model parameters being proportional to that of the process stages of interest occurring during the pulse.

To obtain reliable data on the first, the fastest stages of the energy and charge transfer processes occurring in RC's, it is necessary to use laser pulses much less than a picosecond in width. This is borne out by the gap between the results of the femtosecond spectroscopy of RC's $[15,16]$ and those obtained with the same samples and by the same method but using laser pulses with a duration of 30 40 ps $[47,48]$.

The first studies with a time resolution better than a picosecond of the primary photoprocesses occurring in the RC's of the purple bacteria $R h$. sphaeroides were carried out as far back as 1980 [1113]. No more than a score of similar works have been performed to date, which is explained by the extremely complicated character of the experiments involved. In almost all of these works subject to research have been the following two main moments : the time constants for energy and charge transfer between the pigments of RC's and the role of $B_{L}$ in the electron transfer process.

In the work reported in [11], where use was made for the first time of 0.7 -ps pulses at $610 \mathrm{~nm}$ to excite a sample of $R h$. sphaeroides, it was found that the state $\mathrm{P}^{+} \mathrm{H}_{\mathrm{L}}^{-}$developed with a time constant of 
around 4 ps. But the laser intensity used in the experiments was too high (this was mentioned by the authors themselves and will be demonstrated once more when comparing the results obtained in [11] with the data reported in [19-21]). For this reason, although some $\mathrm{RC}$ state preceding the $\mathrm{P}^{+} \mathrm{H}_{\mathrm{L}}^{-}$one was in fact observed in [11], the authors did not draw any definite conclusions as regards its nature. In the works reported in $[12,13]$, when exciting similar RC's in the H-absorption band (718 nm) with 0.7-ps pulses, they measured the time constant for energy migration from $\mathrm{H}$ to $\mathrm{P}(2 \pm 1 \mathrm{ps})$ and that for electron transfer from $\mathrm{P}$ to $\mathrm{H}(7 \pm 2 \mathrm{ps})$.

Most investigations of RC's with the use of femtosecond-pulse lasers have been performed only in the past three years [14-27]. The femtosecond spectrometer developed at the Institute of Spectroscopy of the USSR Academy of Sciences has been used to study the RC's, both intact and modified with $\mathrm{NaBH}_{4}$, of $R h$. sphaeroides at room temperature. The RC samples were prepared at the Institute of Soil Science and Photosynthesis of the USSR Academy of Sciences (Pushchino, Moscow Region).

The RC's under study were excited with 300-fs pulses at a wavelength of $620 \mathrm{~nm}$ within the absorption band of the dimer $P$ and the monomers $B_{L}$ and $B_{M}[50]$. The optical density of the sample in this region was 0.5 . Figure 3 shows the optical density variation $\Delta A_{870}$ (the subscript denoting the probing pulse wavelength) in the $\mathrm{P}$-absorption band as a function of the excitation intensity $I$, plotted at a delay time between the exciting and probing pulses

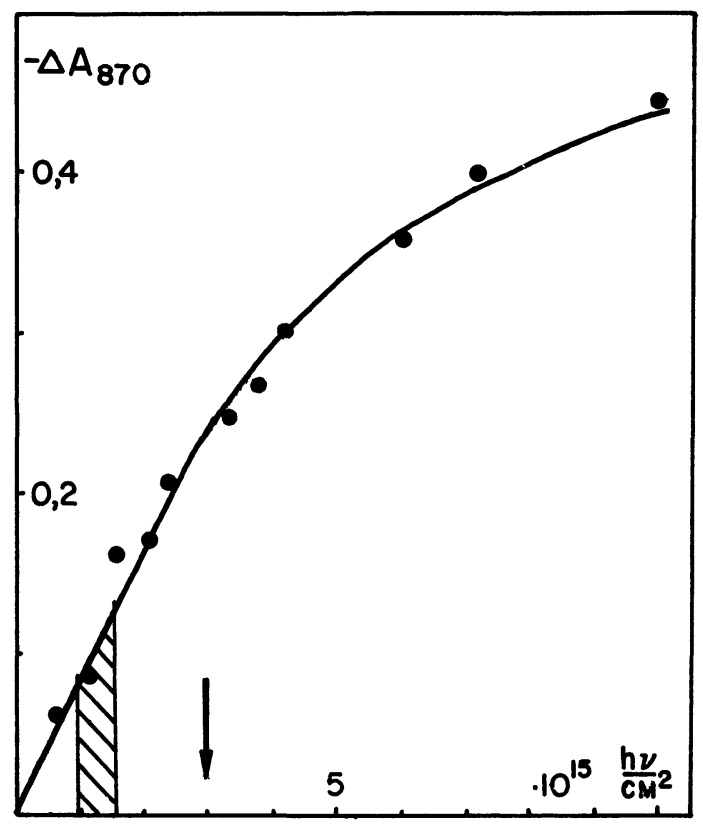

Fig. 3. $-\Delta A_{870}$ kinetics as a function of the excitation intensity $I$ at a delay time of $\Delta t=0.5 \mathrm{ps}$. Dashed area indicates excitation intensities at which the data of Figs. 4, 5 , and 7 were obtained (the arrow marks the excitation intensity at which the $\Delta A_{755}$ kinetics was plotted). of $\Delta t=0.5 \mathrm{ps}$ when the excitation process can be considered to be over (see later in the text). The relationship obtained was used properly to select the experimental excitation intensities. It is clear that use should be made of low intensities if conditions are to be created approximating most closely those under which natural photosynthesis goes on. But lowering the excitation intensity worsens the signalto-noise ratio in the difference spectra. Our investigations were for the most part conducted at an excitation intensity of $10^{15} \mathrm{phot} / \mathrm{cm}^{2}$ which approximately amounted to $0.3 I_{\mathrm{s}}\left(I_{\mathrm{s}}\right.$ being the saturation intensity). Around $10 \%$ of the RC's became excited in this case. When measuring the optical density variation kinetics in the $\mathrm{H}$-absorption band $(775 \mathrm{~nm})$, the excitation intensity was increased up to $I_{\mathrm{s}}$ to improve the signal-to-noise ratio, and this led to the excitation of $30 \%$ of the RC's.

Figures 4 and 5 present optical density variation kinetics plotted for various RC's. In view of the fact that subject to excitation were both the $P$ and B molecules, special attention was paid to the measurement of the kinetics for intact RC's in the Babsorption band $(800 \mathrm{~nm})$ near the isobestic point $(790 \mathrm{~nm})$ for the charge separation process. Characteristic of these kinetics is the rapid emergence and disappearance of bleaching during the exciting pulse [19-21]. The kinetics of figure 4 are normalized on the bleaching basis. We believe that the change in the optical density of the sample at $\Delta t \leqslant 0.5 \mathrm{ps}$ is due to the-excitation of the $B$ monomers and the fast (commensurable with the exciting pulse duration) migration of excitation to the dimer $P$. The time of excitation migration from the $B$ to $P$ molecules, estimated through mathematical modeling, amounts to $150 \pm 100 \mathrm{fs}$ [20]. The increase in the optical density observed to occur in these kinetics at delay times in excess of $0.5 \mathrm{ps}$ results from the absorption by the excited state $\mathrm{P}^{*}$. The occurrence of absorption in this spectral region was observed in [14] when selectively exciting the $\mathrm{P}$ dimer with 150 -fs pulses.

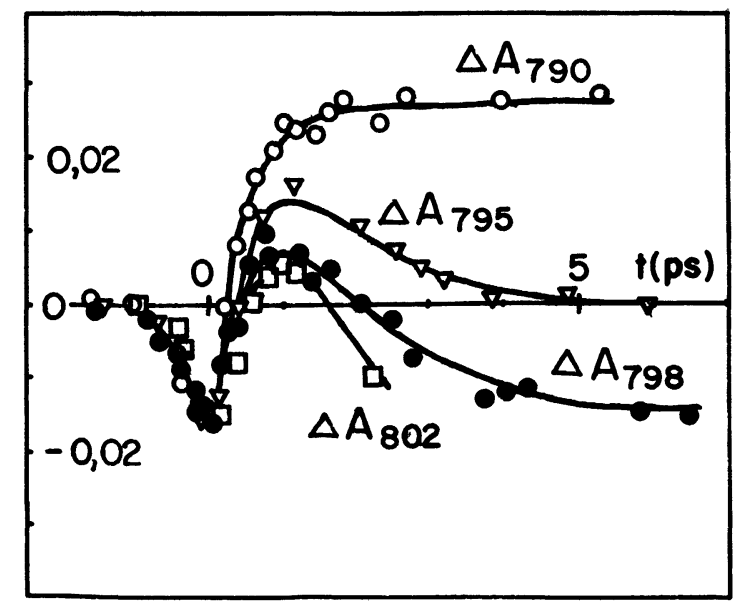

Fig. 4. $-\Delta A$ kinetics in the vicinity of $800 \mathrm{~nm}$ at $I \simeq 10^{15} \mathrm{phot} / \mathrm{cm}^{2}$. 


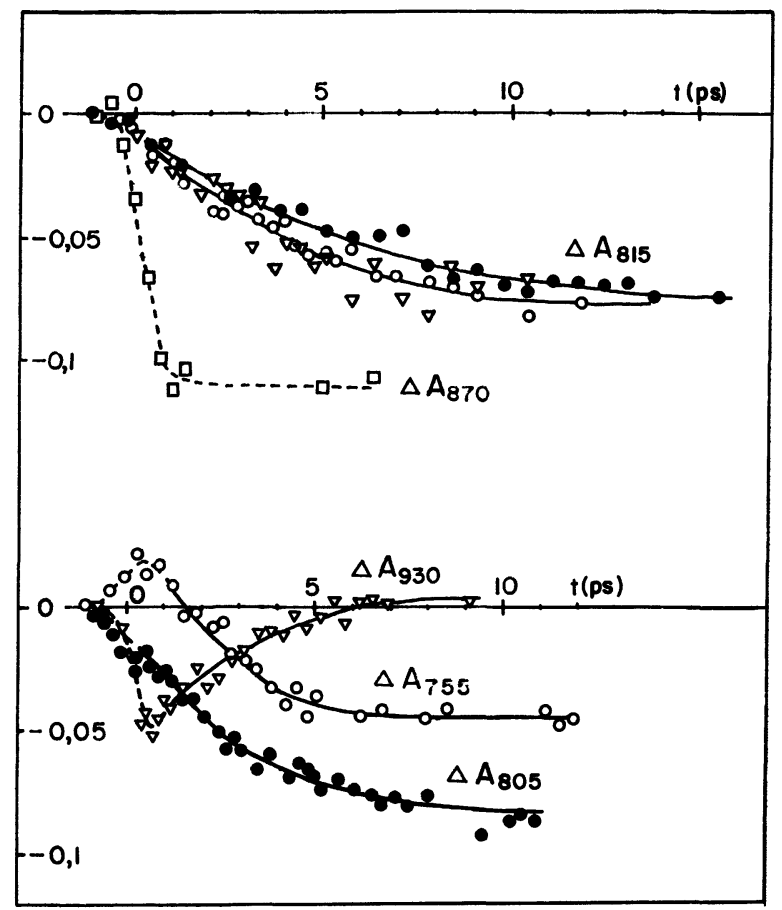

Fig. 5. - Some $\Delta A$ kinetics at various probing pulse wavelengths for intact RC's (top) and for RC's modified with $\mathrm{NaBH}_{4}$ (bottom). Solid lines show results of mathematical processing of experimental data points. For $\Delta A_{815}$ kinetics (top) : open circles - RC's with ubiquinone S removed ; solid circles - RC's with reduced $\mathrm{Q}$; triangles intact RC's.

The further evolution of $\Delta A$ reflects the charge separation process.

As follows from the kinetics of figure 4 and also the kinetics of bleaching in the P-absorption band, $\Delta A_{870}$ (Fig. 5), at a delay time of 0.5 ps the localization of the excitation energy on the dimer $\mathrm{P}$ on the whole comes to an end. The time of charge separation in RC's is approximately an order of magnitude longer, and so the use of excitation at $620 \mathrm{~nm}$ makes it possible to separate in time the excitation of the RC's and charge separation therein. The initial section of the $\Delta A_{870}$ kinetics is to a good approximation a measure of the exciting pulse duration, i.e., it is proportional to the integral of the correlation function of the exciting and probing pulses, the zero delay time marking the coincidence of the maxima of these pulses in the sample.

The migration of excitation from $\mathrm{H}$ and $\mathrm{B}$ to $\mathrm{P}$ has also been studied in the recent works reported in $[15,17,26]$. Based on the similarity between the bleaching kinetics in the $\mathrm{P}$-absorption band $\left(\Delta A_{860}\right)$ obtained upon excitation in the $\mathrm{H}-$, , B-, and $\mathrm{P}-$ absorption bands, they concluded that the time of migration of excitation from $\mathrm{H}$ and $\mathrm{B}$ to $\mathrm{P}$ was short ( $<100 \mathrm{fs})$.

This agrees accurately to within measurement error with our result. It should be noted, however, that when observing kinetics in the P-absorption band at $620 \mathrm{~nm}$, it is a fairly complicated matter to monitor the excitation conditions by the optical density maximum $\Delta A_{\max }$ in the difference spectrum. Indeed, at exciting pulse energies close to $I_{\mathrm{s}}$ $\Delta A_{\max }$ depends but weakly on the pulse energy (see Fig. 3). If the excitation intensity is increased in excess of $I_{\mathrm{s}}$, the contribution to the kinetics observed will come only from the leading edge of the exciting pulse, which will shorten the kinetics. This is illustrated by figure 6 which shows bleaching kinetics for Nile blue plotted at various exciting pulse intensities.

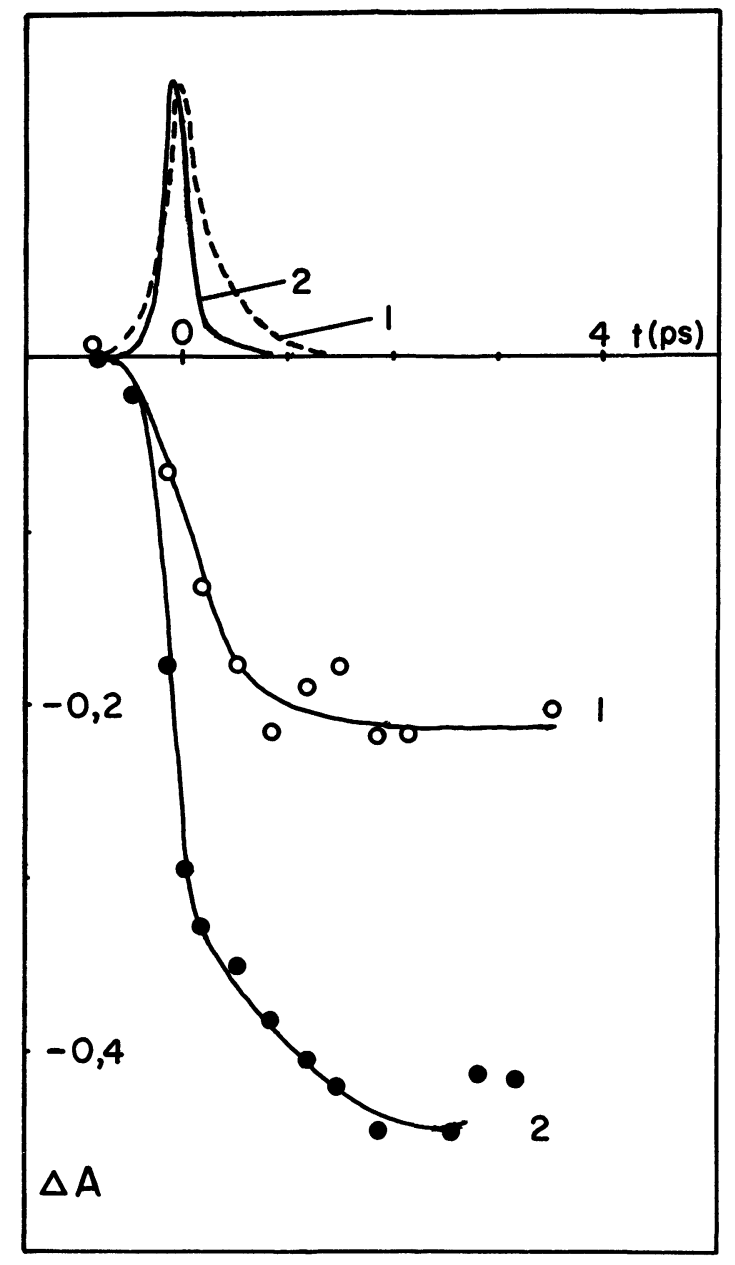

Fig. 6. $-\Delta A$ kinetics plotted for Nile blue at excitation intensities of $6 \times 10^{14} \mathrm{phot} / \mathrm{cm}^{2}(1)$ and $3 \times 10^{15} \mathrm{phot} / \mathrm{cm}^{2}$ (2). Shown at top are normalized time derivatives of the kinetics. The half-widths of these functions are : (1) $250 \mathrm{fs}$ and (2) $150 \mathrm{fs}$.

The excitation energy migration time can evidently be measured more accurately in the vicinity of the isobestic point, since in this spectral region $\Delta A$ changes sign in the course of energy transfer (Fig. 4). Besides, it is easier to monitor here the excitation intensity by the form of the kinetics: variation of the excitation intensity causes qualitative changes in the spectra and kinetics (see Fig. 8). 
Figure 5 presents kinetics reflecting the charge separation process occurring in various RC modifications. The kinetics were mathematically processed for delay times in excess of 0.5 ps. Optimization by the method of least squares under the assumption of monoexponential time dependence yielded the folllowing time constants $\tau$ for the kinetics :

(a) Intact RC

$\begin{array}{lll}\tau_{815} & = & 4.4 \pm 1.5 \mathrm{ps} \\ \tau_{755} & = & 2.4 \pm 0.5 \mathrm{ps}\end{array}$

(b) RC modified with $\mathrm{NABH}_{4}$

$\begin{array}{lll}\tau_{930} & = & 2.7 \pm 0.7 \mathrm{ps} \\ \tau_{805} & = & 3.1 \pm 0.4 \mathrm{ps} \\ \tau_{755} & = & 2.1 \pm 0.3 \mathrm{ps}\end{array}$

(c) $\mathrm{RC}$ with the quinone $\mathrm{Q}_{\mathrm{L}}$ removed $\tau_{815} \quad=\quad 4.4 \pm 0.7 \mathrm{ps}$

(d) $\mathrm{RC}$ with $\mathrm{Q}_{\mathrm{L}}$ reduced $\tau_{815} \quad=\quad 6.2 \pm 0.9 \mathrm{ps}$

Comparison between the values of $\tau_{815}$ for the cases (a) and (d) shows that the reduction of the quinone $Q_{L}$ affects the electron transfer rate even at the earliest charge separation stage. This is also in line with the data reported in $[15,24]$ and is confirmed by the above considerations as to the applicability limits of the redox titration technique.

The charge separation time measured in our experiments agrees well with the data obtained in $[14,26]$ when selectively exciting the dimer P. In both cases, contrary to the earlier suggestions made in the works reported in [12, 33, 35, 42-45], no rapid ( $<1 \mathrm{ps)}$ development of the $\mathrm{P}^{+} \mathrm{B}_{\mathrm{L}}^{-}$state was observed preceding the $\mathrm{P}^{+} \mathrm{H}_{\mathrm{L}}^{-}$state. However, measuring the kinetics alone is not enough categorically to conclude that the $\mathrm{P}^{+} \mathrm{B}_{\mathrm{L}}^{-}$state is not observed at all (as was suggested in the works reported in [14, 26]).

In our works reported in [19, 21-23], we plotted not only the kinetics, but also the difference spectra for various delay times between the exciting and probing pulses (Fig. 7). The following changes are observed to occur in the difference spectra upon charge separation in intact RC's : bleaching occurs at 805 and $755 \mathrm{~nm}$, whereas at $780 \mathrm{~nm}$ the optical density of the sample increases.

Bleaching in the $750 \mathrm{~nm}$ band is believed to be due to the reduction of $\mathrm{H} \mathrm{[50].} \mathrm{Absorption} \mathrm{at} 780 \mathrm{~nm}$ is explained mainly by the shift of the B-absorption band in the field of $\mathrm{P}^{+}$[50]. Attributed to such a band shift was also bleaching at $805 \mathrm{~nm}$ [14]. But in the case of band shift the integral absorption should be comparable with the integral bleaching. In the above spectra, bleaching is much greater than absorption. Even if account is taken of the fact that absorption at $780 \mathrm{~nm}$ is partially compensated by the bleaching of the H-band at $760 \mathrm{~nm}$, the asymmetry of the 780 - and $805-\mathrm{nm}$ bands cannot be explained by

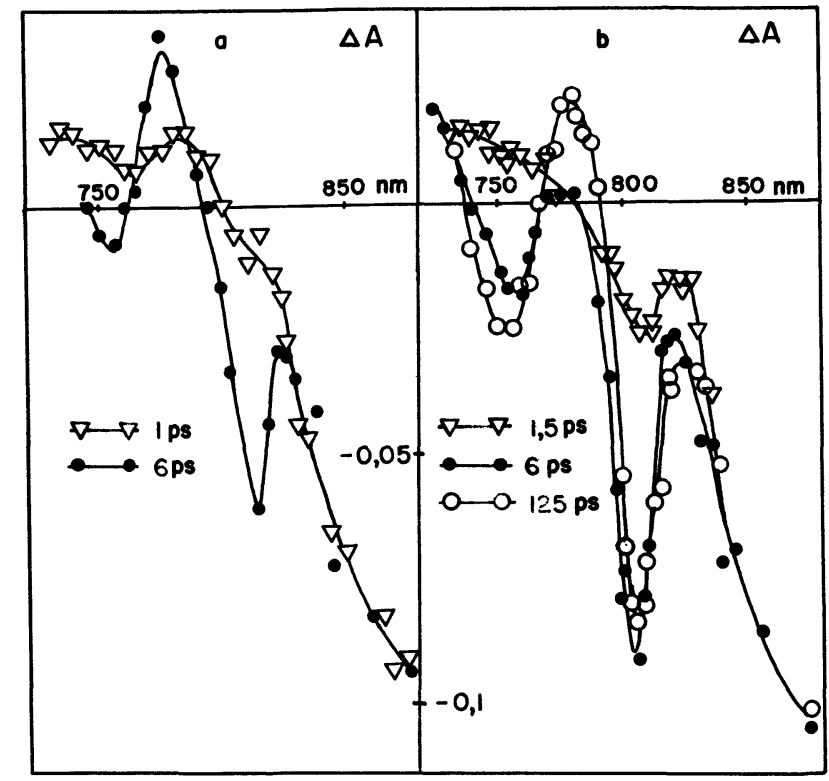

Fig. 7. - Differential spectra of (a) intact RC's and (b) RC's modified with $\mathrm{NaBH}_{4}$ plotted at various delay times. $I \simeq 10^{15}$ phot $/ \mathrm{cm}^{2}$.

the shift of the B-bands alone. We believe that bleaching at $805 \mathrm{~nm}$ is partially due to the reduction of $B_{L}$ upon charge separation $[19,21]$. The spectral changes caused by this process are masked by the changes due to the shift of the $\mathrm{B}_{\mathrm{M}^{-}}$-absorption band in the field of $\mathrm{P}^{+}$. The use of RC's modified with $\mathrm{NaBH}_{4}[22,23]$ made it possible to overcome this difficulty because such RC's have their $B_{M}$ 's almost completely removed [49].

The differential spectra of modified RC's plotted for various delay times relative to the exciting pulse maximum are generally similar to those of intact RC's obtained under the same conditions (Fig. 7). The main differences are in the behaviour of the Bband bleaching maximum and in the absence of absorption in the region of $780 \mathrm{~nm}$ at short delay times. When exposing intact RC's to radiation at $620 \mathrm{~nm}$, at the initial moment (zero delay time) there occurs the bleaching of the B-band with a maximum at $800 \mathrm{~nm}$ as a result of direct excitation of the monomer bacteriochlorophyll molecules. At a delay time of 6 ps the bleaching maximum is shifted to $810 \mathrm{~nm}$ as a result of the shift of the B-absorption band in the field of $\mathrm{P}^{+}$; for the same reason, there occurs absorption at $780 \mathrm{~nm}$. In modified RC's, the bleaching maximum of the $\mathrm{B}_{\mathrm{L}}$-absorption band at $805 \mathrm{~nm}$ does not shift as the delay time is varied from 0 to $6 \mathrm{ps}$, whereas absorption at $780 \mathrm{~nm}$ is practically absent at a delay time of 6 ps (Fig. 7). Both these differences point to the fact that the contribution of the B-band shift to the differential spectra of shift of the $B_{L}$-absorption band is observed only at long delay times (Fig. 7b, delay time $125 \mathrm{ps}$ ), when an electron has left $B_{L}$. 
In the works reported in [26, 47, 49], it was demonstrated that the modification of RC's did not affect the efficiency of electron transfer in the pigment structure, the electron transfer times measured for modified RC's being close to those for their intact counterparts. It is, therefore, quite reasonable to take it that the electron transfer mechanism remains unchanged upon modification. The absence of $\mathrm{B}_{\mathrm{M}}$ and of the associated additional shift of the absorption band allows one to conclude with confidence for the modified RC's that the bleaching of the $\mathrm{B}_{\mathrm{L}}$-absorption band at the early electron transfer stages (delay time $6 \mathrm{ps}$ ) is related mostly to the formation of the $\mathrm{B}_{\mathrm{L}}^{-}$anion-radical and not to the band shift. This means that an electron is transferred from $P$ to both the $\mathrm{H}_{\mathrm{L}}$ and $\mathrm{B}_{\mathrm{L}}$ molecules, which is at variance with the statement that it is only $H_{L}$ that accepts an electron from $P[14,15,26,36]$.

The mathematical processing of the kinetics has shown that the decay rate of $\mathrm{P}^{*}\left(\Delta A_{930}\right)$ coincides accurately to within calculation error with the rate of electron transfer to $\mathrm{H}_{\mathrm{L}}\left(\Delta A_{755}\right)$ and to $\mathrm{B}_{\mathrm{L}}\left(\Delta A_{805}\right)$. Falling outside the error limits is only the difference between the times of electron transfer to $B_{L}$ $(3.1 \pm 0.4 \mathrm{ps})$ and to $\mathrm{H}_{\mathrm{L}}(2.1 \pm 0.3 \mathrm{ps})$. One possible cause of this discrepancy is the fact that the $\Delta A_{755}$ kinetics was plotted at somewhat higher excitation intensities than all the other kinetics because of the low signal-to-noise ratio at wavelength of $755 \mathrm{~nm}$ at low excitation intensities. Although in this case the experiment was still conducted within the linear excitation region (see Fig. 3), the possibility cannot be ruled out that the $\Delta A_{755}$ kinetics was shortened, for the kinetics time constant is very sensitive to any increase in the excitation intensity (see later in the text). If one assumes that the $\Delta A_{755}$ kinetics suffers no distortion upon tripling the excitation intensity, one may then conclude that the transfer of an electron to $\mathrm{H}_{\mathrm{L}}$ leaves that to $\mathrm{B}_{\mathrm{L}}$ behind.

The shortest distances between the macrocycles $\mathrm{P}$ and $\mathrm{B}_{\mathrm{L}}(5.4 \AA), \mathrm{P}$ and $\mathrm{H}_{\mathrm{L}}(12.5 \AA)$, and between $\mathrm{H}_{\mathrm{L}}$ and $\mathrm{B}_{\mathrm{L}}(4 \AA)$, correspond to the times of electron transfer from $P$ to $B_{L}$, accurate to within a few picoseconds, from $B_{L}$ to $H_{L}$ accurate to within a few hundred femtoseconds, and from $\mathrm{P}$ to $\mathrm{H}_{\mathrm{L}}$ accurate to within a few microseconds [23, 51]. For this reason, the possibility of a faster tunnelling of an electron from $P$ to $H_{L}$ than from $P$ to $B_{L}$ seems doubtful [52].

As follows from the $\mathrm{X}$-ray structure analysis data $[28,29]$, apart from the slight difference between the $\mathrm{L}$ and $\mathrm{M}$ proteins associated with the active and inactive branches of RC's, these branches also differ in the arrangement of the phytol tails (Fig. 2). The phytol tails of the $\mathrm{P}_{\mathrm{L}}$ and $\mathrm{H}_{\mathrm{L}}$ molecules are so arranged that they can, in principle, serve as mediators in charge transfer from $\mathrm{P}$ to $\mathrm{H}_{\mathrm{L}}$. If one assumes that the phytol tail of $\mathrm{P}$ pointing to
$H_{L}$ mediates in electron transfer from $P$ to $H_{L}[19$, $21-23,53,54]$, then the possibility cannot be ruled out that an electron is transferred faster to $\mathrm{H}_{\mathrm{L}}$ than to $B_{L}$, but this question requires further investigation.

Taking into consideration the above remarks on the time constants for the kinetics, the electron transfer process can be described within the framework of the following three models :

$$
\begin{aligned}
& \text { (1) } \mathrm{P}^{k_{1}} \rightarrow \mathrm{P}^{+} \mathrm{B}_{\mathrm{L}}^{-} \stackrel{k_{2}}{\rightarrow} \mathrm{P}^{+} \mathrm{H}_{\mathrm{L}}^{-} \\
& \text {(2) } \mathrm{P}^{*} \stackrel{k_{1}}{\rightarrow} \mathrm{P}^{+} \mathrm{H}_{\mathrm{L}}^{-} \stackrel{k_{2}}{\rightarrow} \mathrm{P}^{+} \mathrm{B}_{\mathrm{L}}^{-} \\
& \text {(3) } \mathrm{P}^{+} \mathrm{H}_{\mathrm{L}}^{-} \stackrel{k_{1}}{\rightarrow} \mathrm{P}^{*} \stackrel{k_{2}}{\rightarrow} \mathrm{P}^{+} \mathrm{B}_{\mathrm{L}}^{-}
\end{aligned}
$$

In all the above three models, the electron transfer process ends with the distribution of the electron between $B_{L}$ and $H_{L}$. Model (1) agrees with the mutual arrangement of the $\mathrm{P}, \mathrm{B}_{\mathrm{L}}$, and $\mathrm{H}_{\mathrm{L}}$ macrocycles in RC's [28, 29]. It can be considered if the discrepancy between the kinetics $\Delta A_{755}$ and $\Delta A_{805}$ is disregarded. In this case, a good fit to experiment is obtained with $I / k_{1}=3$ ps and $I / k_{2}=I / k_{3} \leqslant 0.3 \mathrm{ps}$. Models (2) and (3) describe the transfer of an electron in an $\mathrm{RC}$ if the time of transfer from $P$ to $H_{L}$ is shorter than or equal to that of transfer from $P$ to $B_{L}$. In this case, as mentioned above, additional suggestions are necessary concerning the mechanism of electron transfer from $\mathrm{P}$ to $\mathrm{H}_{\mathrm{L}}$. Model (2) agrees with experiment if we put $I / k_{1}=2.9 \mathrm{ps}$ and $I / k_{2}=I / k_{3} \leqslant 0.6 \mathrm{ps}$. Model (3) can describe both simultaneous transfer of electrons from $P$ to $B_{L}$ and $H_{L}$ and independent transfer at different rates in the case of heterogeneous RC's. To make model (3) fit experimental data, we have put $I /\left(k_{1}+k_{2}\right)=3$ ps. The ratio $k_{1} / k_{2}$ in this case must correspond to the ratio between the fraction of electron localization $\mathrm{H}_{\mathrm{L}}$ and that of electron localization on $\mathrm{B}_{\mathrm{L}}$. The lack of precise data on the absorption cross sections of $\mathrm{H}_{\mathrm{L}}$ and $\mathrm{B}_{\mathrm{L}}$ makes these fractions difficult to estimate correctly. If we take it that the molar extinction coefficient $\varepsilon$ for a single bacteriochlorophyll molecule in an RC amounts to about $50 \%$ of $\varepsilon$ for $P$ at $870 \mathrm{~nm}$ and that $\varepsilon$ for $B_{L}$ is around $1.4 \varepsilon$ for $P$ [12], the bleaching of the $\mathrm{H}_{\mathrm{L}}^{-}$and $\mathrm{B}_{\mathrm{L}}$-absorption bands may then correspond to the reduction of $50 \%$ of $\mathrm{B}_{\mathrm{L}}$.

Our experiments point to the fact that the $\mathrm{B}_{\mathrm{L}}$ bacteriochlorophyll molecule takes part in the electron transfer process occurring in RC's. The question as to the primary electron acceptor remains open and requires further investigation. We can only state that the transfer of an electron both to $\mathrm{H}_{\mathrm{L}}$ and to $\mathrm{B}_{\mathrm{L}}$ occurs within no less than 2-3 ps. The exchange of an electron, if any, between $\mathrm{P}^{+} \mathrm{H}_{\mathrm{L}}^{-}$and $\mathrm{P}^{+} \mathrm{H}_{\mathrm{L}}^{-}$takes at least a factor of 5-10 less time.

We have already mentioned earlier that the primary processes occurring in RC's depend fairly criti- 
cally on the exciting pulse intensity. This is illustrated by figures 8 through 10 which present differential spectra and kinetics plotted at an excitation intensity of around $3 I_{\mathrm{s}}$. Increasing the excitation intensity several times over in the vicinity of $I_{\mathrm{s}}$ leads to a radical change in the form and characteristic times of the kinetics: thus, with the excitation intensity increased from (0.3) $I_{\mathrm{s}}$ to $3 I_{\mathrm{s}}$, the relaxation time of the initial bleaching $\Delta A_{804}$ increases from 0.15 to $1.5 \mathrm{ps}$, no sign reversal being observed to occur in $\Delta A$ in this case (Fig. 8). Comparing figures 4,8 , and 9 with the data of the work reported in [11], it can be concluded that the authors used excitation intensities much in excess of $I_{\mathrm{s}}$. Therefore, the fast bleaching observed at $800 \mathrm{~nm}$ in [11] was due to processes occurring in overexcited RC's and not to the reduction of $B_{L}$ upon charge transfer as suggested in the work reported in [13]. It also follows from the kinetics of figures 8 and 9 that the relaxation of bleaching at 795 and $804 \mathrm{~nm}$ does not reflect the transfer of energy or charge from $\mathrm{B}$ to $\mathrm{H}$, for the $\Delta A_{755}$ kinetics has a different characteristic time in the H-absorption band. Comparison between our

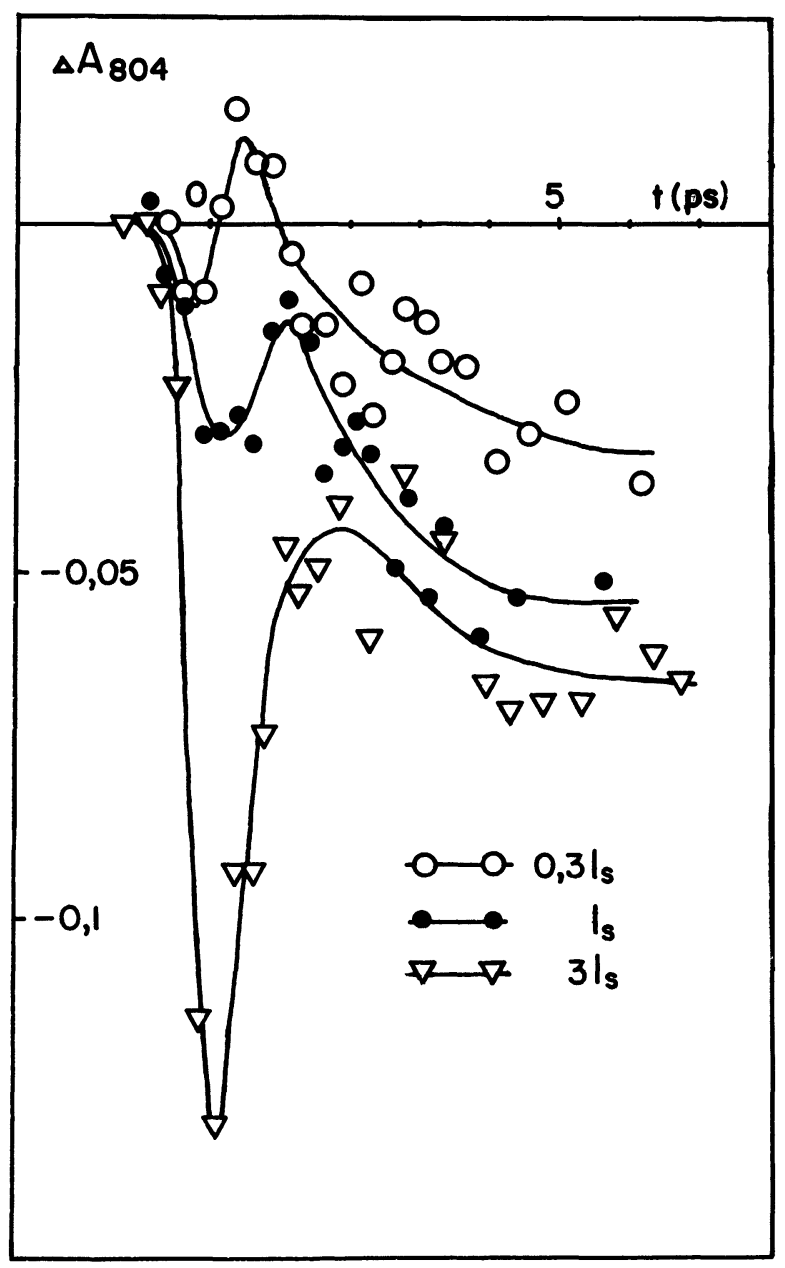

Fig. 8. $-\Delta A_{804}$ kinetics (intact RC's) for various excitation intensities.

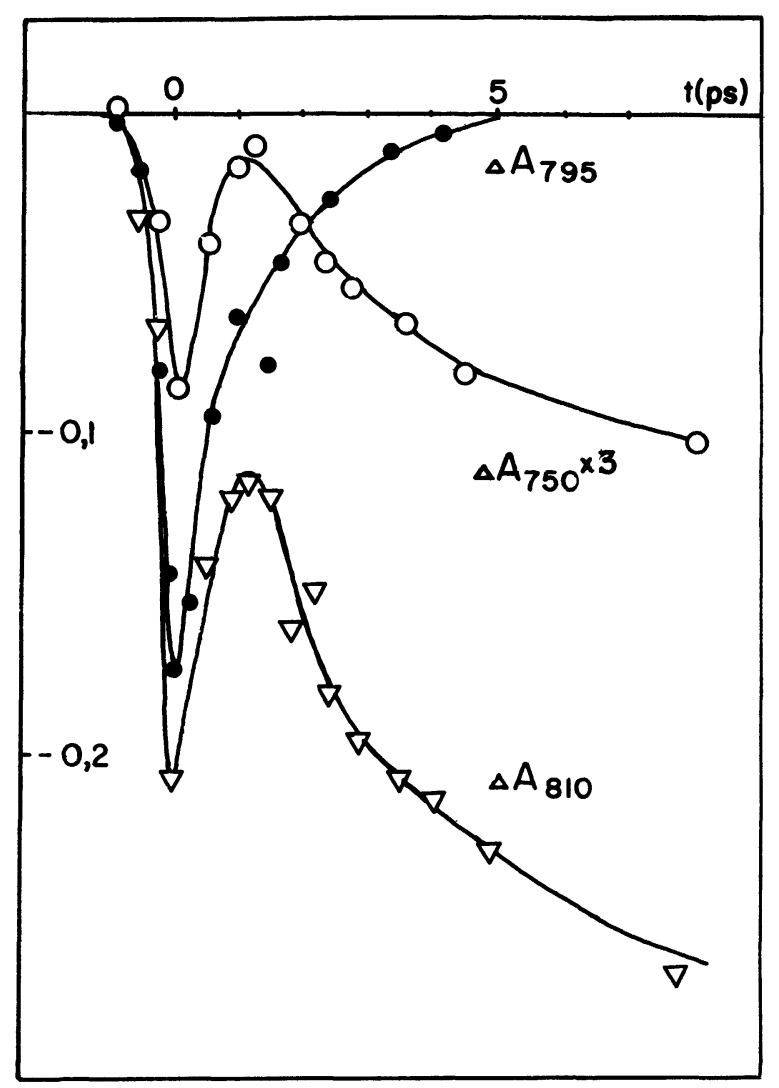

Fig. 9. $-\Delta A$ kinetics for various wavelength at $I \simeq 10^{16}$ phot $/ \mathrm{cm}^{2}$ (intact RC's).

data and the $\Delta A_{800}$ kinetics reported in $[15,26]$ allows us to contend that this kinetics was also obtained upon overexcitation of RC's. This is borne

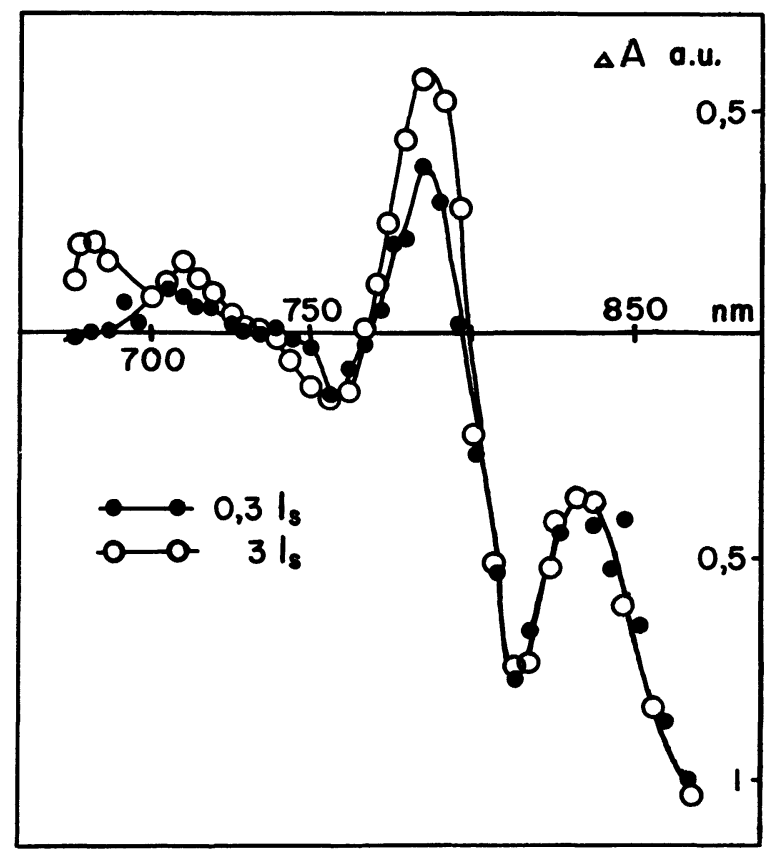

Fig. 10. - Differential spectra for various excitation intensities (intact RC's, delay time $30 \mathrm{ps}$ ) normalized on $\Delta A_{870}$. 
out by the absence of the $\Delta A$ sign reversal in the kinetics (with the excitation intensity being low enough, such a sign reversal is observed to occur as the excitation energy migrates from $B$ to $P$ [see Fig. 4]).

Increasing the excitation intensity at $620 \mathrm{~nm}$ leads to the appearance of a large number of RC's having their P and B molecules excited simultaneously. The processes occuring in such RC's differ essentially from those in the case of linear excitation. Even at a

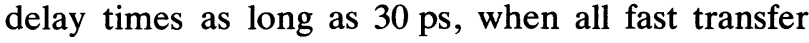
processes have come to an end, the differential spectra plotted at different excitation intensitites differ materially (Fig. 10). Studying the behaviour of RC's at high excitation intensities makes it possible to gain an insight into the charge and energy transfer processes occurring in « closed » RC's, i.e., in condi- tions where excitation reaches an $\mathrm{RC}$ that has already absorbed a quantum and is in the process of charge transfer. What is more, such investigations are of independent interest from the standpoint of studying transfer process occurring in RC's as in aperiodic crystals.

\section{Acknowledgements.}

The authors wish to express their gratitude to Academician A.A. Krasnovskii and Professor V.S. Letokhow for many fruitful discussions and their support of this work and also to V.A. Shuvalov, A.V. Klevanik, and A.Ya. Shkuropatov who provided the samples and took part in some of the experiments.

\section{References}

[1] Chekalin, S.V., Kryukov, P.G., Matveets, Yu.A., Shatberashvili, O.B., Opto-Electronics 6 (1974) 249-261.

[2] Bradlay, D.J., Ultrashort Light Pulses, Ed. Shapiro S.L. (Berlin, New-York, Springer-Verlag) 1977, ch. 2, p. 18.

[3] Rockley, M.G., Windsor, M.W., Cogdell, R.J., PARSON, W.W., Proc. Natl. Acad. Sci. USA 72 (1975) 2251-2258.

[4] Kryukov, P.G., Matveets, Yu.A., Shmchischen, V.A., Kvantoveye Elektron. 7 (1980) 2437-2442.

[5] Matveets, Yu.A., Chekalin, S.V., Sharkov, A.V., J. Opt. Soc. Am. B. 2 (1985) 634-639.

[6] Sharkov, A.V., Palulev, A.V., Chekalin, S.V., Matveets, Yu.A., Biochim. Biophys. Acta. 808 (1985) 94-102.

[7] Sharkov, A.V., Matveets, Yu.A., Pakulev, A.V., CheKalin, S.V., Doklady Akad. Nauk SSSR 281 (1985) 466-470.

[8] Matveets, Yu.A., Semchischen, V.A., Kvantovaya Elektron. 6 (1979) 848-850.

[9] Fork, R.L., Greene, B.I., Shank, C.V., Appl. Phys. Lett. 38 (1981) 671-672.

[10] Diels, J.C., MCMichael, I.C., Fontaine, J.J., WANG, C.Y., 3rd Topical Meeting on Picosecond Phenomena, Garmisch-Partenkirchen (1982).

[11] Holten, D., Hogansaon, C., Windsor, M.W., Schenck, C.C., Parson, W.W., Migus, A., FORK, R.L., SHANK, C.V., Biochim. Biophys. Acta. 592 (1980) 461-477.

[12] Klevanik, A:V., Kryukov, P.G., MatVeets, Yu.A., Semchischen, V.A., Shuvalov, V.A., Pis'ma ZhETF 32 (1980) 107-111.

[13] Klevanik, A.V., Kryukov, P.G., Matveets, Yu.A., Semchischen, V.A., Shuvalov, V.A., Doklady Akad. Nauk SSSR 256 (1981) 483-486.

[14] Martin, J.L., Breton, J., Hoff, A.J., Migus, A. Antonetti, A., Proc. Natl. Acad. Sci. USA 83 (1986) $957-961$.
[15] Breton, J., Martin, J.L., Migus, A., Antonetti, A., Orszag, A. in Ultrafast Phenomena $V$ Eds Fleming G.R., Siegman A.E., pp. 393-397 (Springer-Verlag, Berlin) 1986.

[16] Becker, M. Middendorf, D., WoOdbury, N.W., PARSON, W.W., BLANKENSHIP, R.E., Ibid. pp. 374-378.

[17] ZinTH, W. DOBER, J., KaISER, W., Ibid. pp. 379-383.

[18] Wasielewski, M., Tiede, D.M., Frank, H.A., Ibid., pp. 388-392.

[19] Chekalin, S.V., Matveets, Yu.A., Yartsev, A.P., Ibid., pp. 402-405.

[20] Matveets, Yu.A., Chekalin, S.V., Yartsev, A.P., Pis'ma ZhETF 43 (1986) 546-548.

[21] Matveets, Yu.A., Chekalin, S.V., Yartsev, A.P., Doklady Akad. Nauk SSSR 292 (1987) 724-728.

[22] Matveets, Yu.A., Chekalin, S.V., Shkuropatov, A.Ya., Shuvalov, V.A., YarTSEv, A.P., Doklady Akad. Nauk USSR 294 (1987) 1480-1485.

[23] Chekalin, S.V., Matveets, Yu.A., Shkuropatov, A.Ya., Shuvalov, V.A., YARTSEV, A.P., FEBS Lett. 216 (1987) 245-248.

[24] Woodbury, N.W.T., Becker, M., Middendorf, D. PARSON, W.W., Biochemistry 24 (1985) 7516-7521.

[25] Breton, J., martin, J.L., Migus, A., Antonetti, A., Otszag, A., Proc. Natl. Acad. Sci. USA 83 (1986) 5121-5125.

[26] Breton, J., Martin, J.L., Petrich, J., Migus, A. AntonetTI, A., FEBS Lett. 209 (1986) 37-43.

[27] ZinTh, W., Nuss, M.C., Franz, M.A., Kaiser, W., MiCHEL, H. in Antennas and Reaction Centers of Photosynthetic Bacteria, Ed. Michel-Beyerle M.E. (Springer-Velag, Berlin) 1985, pp. 286291.

[28] Diesenhofer, J., Epp, O., Miki, K., Huber, R., Michel, H., J. Mol. Biol. 180 (1984) 385-398.

[29] Diesenhofer, J., Epp, O., Miki, K., Huber, R., Michel, H:, Nature 318 (1985) 618-624. 
[30] Allen, J.P., Feher, G., Yeats, T.O., Rees, D.C., Diesenhofer, J., MiCHEl, H., HubER, R., Proc. Natl. Acad. Sci. USA 83 (1986) 8589-8593.

[31] Feher, G., OKamura, M.Y., Brookhaven Symp. Biol. 28 (1977) 183-194.

[32] Van Grondelle, R., Romijn, J.C., Holmes, N.G., FEBS Lett. 72 (1976) 187-192.

[33] Shuvalov, V.A., Krasnovsky, A.A. in Sov. Sci. Rev. Section D, Biology Reviews Ed. Skulachev V.P. (1982) vol. 3, pp. 1-24.

[34] Netzel, T.L., Rentzepis, P.M., Tiede, D.M., Prince, R.C., DutTon, R.L., Biochim. Biophys. Acta 460 (1977) 467-478.

[35] Shuvalov, V.A., KlevaniK, A.V., FEBS Lett. 160 (1983) 51-55.

[36] Borisov, A.Yu., Danielus, R.V., Kudzmauskas, S.P., Piskarskas, A.S., RaziIVIN, A.P., SirutKaITIS, V.A., VAlKunas, L.L., Photochem. Photophys. 6 (1983) 33-38.

[37] Kaufman, K.J., Dutton, P.L., Netzel, T.L., LeIGH, J.S., RENTZEPIS, P.M., Science 188 (1975) 1301-1304.

[38] Parson, W.W., Ann. Rev. Biophys. Bioeng. 11 (1982) 57-80.

[39] Maroti, P., Kirmaier, C., Wraight, C., Holten, D., Pearlstein, R., Biochim. Biophys. Acta 810 (1985) 132-139.

[40] Kirmaier, C., Holten, D., Parson, W.W., Biochim. Biophys. Acta 810 (1985) 33-48.

[41] Kirmaier, C., Holten, D., Parson, W.W., FEBS Lett. 185 (1985) 76-82.

[42] Shuvalov, V.A., Klevanik, A.V., Sharkov, A.V., MatVeets, Yu.A., Kryukov, P.G., FEBS Lett. 91 (1978) 135-139.

[43] Kryukov, P.G., Letokhov, V.S., MatVeets, Yu.A., Nikogosyan, D.N., Sharkov, V.A. in
Picosecond Phenomena, Eds. Shank C.V. et al. (Springer, Berlin) 1978, pp. 158-166.

[44] Shuvalov, V.A., KlevaniK, A.V., Sharkov, A.V., Matveets, Yu.A., Kryukov, P.G., Doklady Akad. Nauk USSR 243 (1978) 10721075.

[45] BARbER, J., Nature (1985) 278-279.

[46] Akhmanov, S.A., Borisov, A.Yu., KozlovskiI, V.S., RAzZhivin, A.P., Gadonas, R.A., Danelyus, R.V., PISKarsKas, A.S., Nelineinaya Optika (Nonlinear Optics), Proc. 6th Vavilov Conf., Novosibirsk 1979, pp. 74-84.

[47] Shuvalov, V.A., Duysens, L.N.M., Proc. Natl. Acad. Sci. USA 83 (1986) 1690-1694.

[48] Shuvalov, V.A., VAsmel, H., Amesz, J., DuYSENS, L.N.M., Biochim. Biophys. Acta 851 (1986) 350-357.

[49] Shuvalov, V.A., ShKuropatov, A.Ya., KulakoVA, S.M., Ismailov, M.A., ShKuropatova, V.A., Biochim. Biophys. Acta 849 (1986) 337346.

[50] Clayton, R.K., Photosynthesis (London, NewYork, Rochelle, Melbourne, Sydney, Cambridge University Press) 1980.

[51] Shuvalov, V.A. (1984) in Advances in Photosynthesis Research, Ed. Sybesma, C. (The Hague, M. Nijhoff/Dr. W. Junk) pp. 93-100.

[52] Netzel, T.L. (1982) in Biological Events Probed by Ultrafast Laser Spectroscopy Ed. Alfano R.R., p. 92.

[53] Warman, J.M., De haAs, M.P., Paddon-Row, M.N., Cotsaris, E., Hush, N.S., OEvering, H., Verhoeven, J.W., Nature 320 (1986) 615619.

[54] Heitele, H., Michel-Beyerle, M.E., Finckh, P., Chem. Phys. Lett. 134 (1987) 273-278. 